Document downloaded from:

http://hdl.handle.net/10251/122917

This paper must be cited as:

Benajes, J.; Novella Rosa, R.; Pastor Enguídanos, JM.; Hernández-López, A.; Kokjohn, SL. (2018). Computational optimization of a combustion system for a stoichiometric DME fueled compression ignition engine. Fuel. 223:20-31. https://doi.org/10.1016/j.fuel.2018.01.02

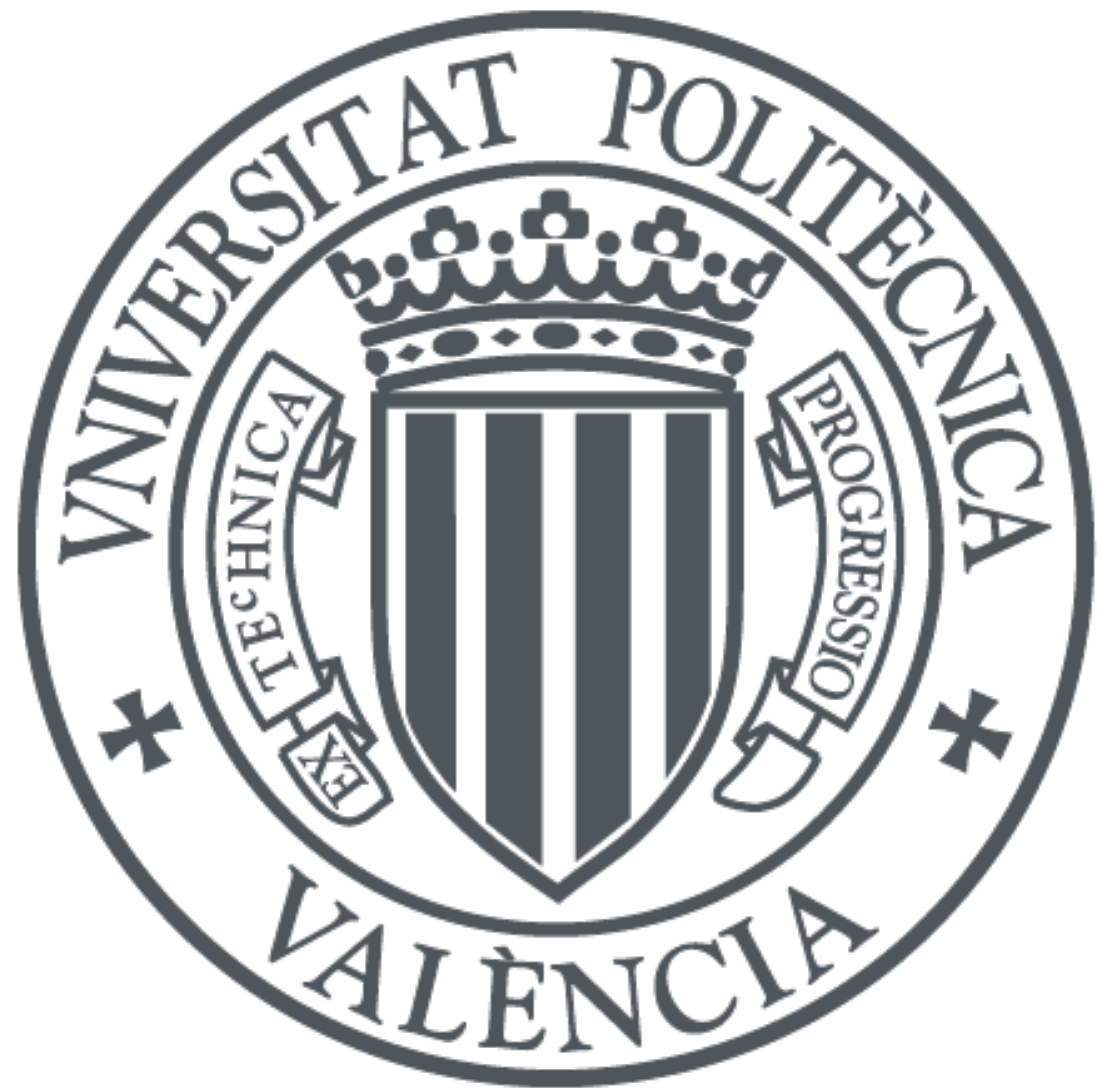

The final publication is available at

http://doi.org/10.1016/j.fuel.2018.01.02

Copyright Elsevier

Additional Information 


\title{
Computational Optimization of a Combustion System for a Stoichiometric DME Fueled Compression Ignition Engine
}

\author{
Jesús Benajes, Ricardo Novella, Jose Manuel Pastor, Alberto Hernández-López \\ CMT-Motores Térmicos \\ Universitat Politècnica de València \\ Camino de Vera s/n, 46022, Valencia (Spain) \\ Sage Kokjohn \\ Engine Research Center, Department of Mechanical Engineering \\ University of Wisconsin-Madison \\ 1018A Engineering Research Bldg, 1500 Engineering Drive, Madison, WI 53706 (USA)
}

\section{Abstract}

An optimization methodology based on a genetic algorithm coupled with the KIVA computational fluid dynamics (CFD) code is applied to the design of a combustion system of a heavy-duty diesel engine fueled with dimethyl ether (DME) and working with stoichiometric combustion in order to equip the system with a three way catalyst (TWC) to control the NOx emissions. The target of the optimization is to improve net indicated efficiency (NIE) while keeping NOx emissions, peak pressure and pressure rise rate under the reference engine levels. The results of the study provide an optimum configuration that offers a $0.6 \%$ NIE improvement while satisfying the restrictions and offering NOx values lower than $1 \%$ of the original emissions. Due to the methodology, not only the optimum combustion system configuration is presented, but also the cause-effect relation of the most relevant inputs with the optimization outputs are identified and analyzed. The new geometry shape reduced heat transfer losses by minimizing the surface area. Injection pressure and swirl proved to be key parameters necessary to overcome the increased mixing requirements of stoichiometric operation. EGR was found to simultaneously increase NIE while controlling NOx emissions. The results show the potential of stoichiometric compression ignition operation using DME as a promising pathway to maintain diesel-like efficiency, while achieving near zero NOx and soot emissions.

Keywords:

Diesel Engine, Alternative Fuels, Pollutant Emissions, Engine Efficiency, Engine Optimization, Three Way Catalyst, Stoichiometric combustion 


\section{Definition of Acronyms}

\begin{tabular}{ll} 
ATDC & After Top Dead Center \\
ACT & Apparent combustion time \\
CAD & Crank Angle Degree (degrees to top dead center) \\
CARB & California Air Resources Board \\
CFD & Computational fluid dynamics \\
CO & Carbon monoxide \\
COSSO & Component Selection and Smoothing Operator \\
DEF & diesel exhaust fluid \\
DME & Dimethyl ether \\
Dnoz & Nozzle hole diameter \\
dS & Cell size \\
EGR & Exhaust gas recirculation \\
ERC & Engine Research Center \\
EVO & Exhaust valve opening \\
GA & Genetic algorithm \\
HCCI & Homogenous charge compression ignition \\
HD & Heavy Duty \\
HRR & Heat release rate \\
IMEP & Gross indicated mean effective pressure \\
IP & Injection pressure \\
IVC & Intake valve closure \\
KH & Kelvin Helmholtz \\
LDEF & Lagrangian-Drop and Eulerian-Fluid \\
LEA & Low-Excess-Air \\
LNT & Lean-NOx-Trap \\
maxPRR & Maximum pressure rise rate \\
NA & Nozzle angle \\
NIE & Net indicated efficiency \\
NSGAII & Non-dominated sorting genetic algorithm \\
PIVC & Pressure at IVC \\
PP & Peak cylinder pressure \\
RCCI & Reactivity Controlled Compression Ignition \\
RSM & Root-mean-square \\
RT & Rayleigh Taylor \\
SCR & Selective catalytic reduction \\
SOI & Start of injection \\
TWC & Three way catalyst \\
UHC & Unburned hydrocarbons \\
WSR & Well Stirred Reactor \\
\hline &
\end{tabular}

\section{Introduction}

Recent research on combustion systems, especially those applied to road and rail transport applications, is focused on improving the fuel consumption while keeping the 
pollutants under the regulation standards. Diesel (compression ignition) engines are one of the most efficient engines in the world. They are known as economical and robust, but also for their smoke and NOx emissions levels [1]. Different emissions control strategies can be used to control pollutant depending if they are applied during or after the combustion process. The techniques applied directly to the combustion process include Low Excess Air (LEA) burn [2] and Exhaust Gas Recirculation (EGR) [1] [3]. EGR is a widely used technique to control NOx emissions; however, high levels of EGR have a noticeable impact on engine efficiency and particulate matter emissions, forcing the research community to find new ways to further control NOx. Current production diesel engines are often equipped with Selective Catalytic Reduction (SCR) or a Lean NOx Trap (LNT) for post-treatment of NOx in the exhaust stream [4]. Although SCR and LNT systems can effectively control NOx emissions, challenges with these systems warrant exploration of alternative methods for emissions control. LNT systems struggle to reach the high NOx conversion efficiencies required to meet current and future regulations over the wide range of conditions experienced during engine operation [5]. Additionally, LNT systems often increase fuel consumption due to periodic rich operation required for regeneration. Urea SCR systems typically have much higher NOx conversion efficiency than LNT systems (conversion efficiencies can be in the range of $90 \%$ to $95 \%$ ); however, diesel exhaust fluid (DEF) dosing required for NOx reduction may increase the overall operational cost compared to a non-SCR equipped engine. Additionally, SCR systems struggle to achieve high NOx conversion efficiencies at temperatures below approximately $200{ }^{\circ} \mathrm{C}$ due to deposit formation from DEF dosing [6] and poor catalyst activity [7]. Currently, SCR equipped heavy-duty diesel engines are capable of meeting current regulated NOx emissions limits on the order of $0.268 \mathrm{~g} / \mathrm{kWh}$. However, the California Air Resources Board (CARB) has proposed future NOx targets of $0.0268 \mathrm{~g} / \mathrm{kWh}$ [8]. Reaching this level of tailpipe NOx with a urea SCR system will likely be challenging. That is, NOx conversion efficiencies would need to be on the order of $99 \%$.

An alternative approach to enable low NOx emissions is the use of stoichiometric operation coupled with a three way catalyst (TWC). The TWC is a widely used technique, is low cost, and can reach a NOx reduction over 99\% [9]. The drawback is that, because stoichiometric operation is required, use with diesel fueled engines has 
resulted in extremely high soot emissions [10] [11] [12]. An alternative approach is to couple stoichiometric operation with a low sooting fuel. One such fuel is dimethyl ether (DME). DME has comparable combustion characteristics to those of diesel fuel [13], but produces no soot emissions even under stoichiometric operation [14] [15] [16].

The literature shows some previous research in the field of engines fueled with DME that shows the potential of the fuel. An optimization of a DME fueled engine with the micro-genetic algorithm was performed by Hyung et al [17]. The results demonstrated the advantage of the non-sooting nature of DME fuel that allows breaking the NOx-soot trade-off that affects diesel engines just optimizing engine settings. For that reason, new strategies for low NOx emissions and high efficiency can be tested with the new fuel that would not be possible to apply to a diesel fueled engine due to soot restrictions. These conclusions were tested experimentally by Park et al [18]. Further work has been done including a piston geometry coupled with injection settings optimization by Park et al. [19]. The optimum geometry was shifted from the conventional diesel reentrant shape to a bathtub type shape coupled with earlier SOI, designing a new combustion chamber with lower emissions without efficiency penalization. An equivalent optimization was also performed for the original engine fueled with diesel and the results present an optimum with lower emissions, but an unavoidable increase in fuel consumption, proving the potential of DME compression ignition operation.

In the present study, we take advantage of the non-sooting nature of DME and apply a TWC in order to achieve future pollutant regulation standards. Under stoichiometric operating conditions, it is expected that complete oxygen utilization will be challenging, potentially requiring changes to the combustion system geometry (e.g., piston bowl shape). The present study computationally optimizes a combustion system for a Heavy Duty (HD) compression ignition engine fueled with DME working with stoichiometric combustion and presents a pathway to maintain diesel-like efficiency while meeting future NOx targets. 
Computational Optimization of the Combustion System of a Heavy Duty Direct Injection Diesel Engine Operating with Dimetyl-Ether

\section{Methods}

\subsection{Experimental setup}

The engine used is a single cylinder version of a Caterpillar C-15, 15-L six-cylinder engine. Table 1 shows the engine and injector specifications. The C-15 is typical of a heavy-duty size-class diesel engine with a bore of $137 \mathrm{~mm}$ and a stroke of $171 \mathrm{~mm}$ yielding a displacement of 2.5 liters per cylinder.

Table 1 - Engine and Injector Specifications.

\begin{tabular}{|l|l|}
\hline Engine Specifications \\
\hline Displacement [L/cylinder] & 2.5 \\
\hline Bore x Stroke [mm] & 137 x 171 \\
\hline Compression Ratio [-] & $17: 1$ \\
\hline Swirl Ratio [-] & 0.7 \\
\hline IVC [deg aTDC] & -154 \\
\hline EVO [ deg aTDC] & 113 \\
\hline Fuel Injector & 6 \\
\hline Number of Holes & 0.214 \\
\hline Hole Diameter [mm] & 130 \\
\hline Included Spray Angle[deg] &
\end{tabular}

The engine was operated at $1800 \mathrm{rev} / \mathrm{min}$ and a nominal load of $18 \mathrm{bar}$ gross indicated mean effective pressure (IMEP) (i.e., near the rated power condition). For the validation tests carried out using diesel fuel, the fueling was held constant and the SOI timing was swept from -18 to -3 deg aTDC. The EGR rate, intake pressure, and intake temperature were held constant at $25 \%, 3.1 \mathrm{bar}$, and $60^{\circ} \mathrm{C}$, respectively. Details of the operating condition and its related settings are included in Table 2.

Table 2 - Operating conditions for model validation experiments [20].

\begin{tabular}{|l|l|}
\hline Nominal gross IMEP [bar] & 18 \\
\hline Speed [rpm] & 1800 \\
\hline Intake Temperature [K] & 333 \\
\hline Coolant Temperature [K] & 353 \\
\hline EGR Temperature [K] & 333 \\
\hline Intake Pressure [bar] & 3.1 \\
\hline SOI Timing - command [deg aTDC] & -18 to -3 \\
\hline Fuel Mass [mg/cycle] & 252 \\
\hline EGR Rate [\%] & 25 \\
\hline Motored Temperature at TDC [K] & 1018 \\
\hline Motored Pressure at TDC [bar] & 147 \\
\hline Injection Pressure [bar] & 1800 \\
\hline Fuel & Halterman Certification Diesel \\
\hline
\end{tabular}




\subsection{Computational Approach}

Computations were performed using an in-house computational fluid dynamics code based on the KIVA-3v release 2 platform [21] with improvements to many physical and chemistry models developed at the Engine Research Center (ERC) [22], [23], [24]. To reduce computing time, simulations consider a sector of the combustion chamber, representing a single nozzle hole of the six hole fuel injector. Additionally, the simulations are restricted to the closed engine cycle, from intake valve closure (IVC) to exhaust valve opening (EVO). The simulations were initialized using solid body rotation to specify the azimuthal velocity flow field at IVC. This section provides an overview of the physical models important to the present study.

\subsubsection{Combustion Model}

The KIVA-3v code is coupled with the SpeedCHEM [25] solver for detailed chemistry calculations. The RNG k- $\varepsilon$ model [26] is used for the turbulence calculations; however, sub-grid turbulence-chemistry interactions are not considered. That is, the current implementation of the SpeedCHEM solver considers every computational cell to be a Well Stirred Reactor (WSR) and the cell average species production rates are assumed to be equal to the species production rates evaluated at the average cell conditions. At each time step, species concentrations and thermodynamic conditions are passed to the chemistry solver for each computational cell. The chemistry solver then integrates the mass and energy equations at constant volume over a period of time equal to the computational time step. Although, sub-grid scale turbulent-chemistry interactions are not considered, by coupling the chemistry solver with the CFD code, the effects of turbulence on combustion are accounted by modeling the effects of turbulence on property transport, heat flux, and mixture formation. Justification for this modeling approach has also been discussed by Kokjohn and Reitz [27].

The chemistry of dimethyl ether was simulated using a reduced reaction mechanism for consisting of 29 species and 66 reactions [28]. Validation simulations of conventional diesel combustion were carried out using n-heptane as surrogate and describing its oxidation by a reduced reaction mechanism made up of 45 species and 142 reactions [23]. 


\subsubsection{Spray Model}

The spray model employed in this study uses the Lagrangian-Drop and EulerianFluid (LDEF) approach. Because a detailed chemistry model is used, it is desirable to use a relatively coarse computational mesh; however, severe grid size dependency has been observed in LDEF spray models. The problem is most severe in the near nozzle region where the droplets are very close together and occupy only small portions of the Eulerian mesh cell. Abraham [29] showed that accurate modeling of the near nozzle region required grid resolution on the order of the orifice diameter. However, it is not feasible from a computational time standpoint to solve engine problems on such a fine mesh. Furthermore, a fundamental assumption of the LDEF approach is that the volume fraction of droplets in each cell is small, that is, the void fraction is near unity. Thus, this assumption may be violated if the mesh size is overly refined up to a mesh size of the order of the droplet size. In order to reduce the grid size dependency of the LDEF spray model and allow accurate spray simulation on a relatively coarse grid, the Gasjet model of Abani et al. [24], [30] is employed to model the relative velocity between the droplets and gas phase in the near nozzle region. Their approach assumes that the relative velocity between a given droplet and its surrounding gas phase is equal to that between the droplet and a turbulent gas jet with the same mass and momentum flux of that of the injected fuel spray. This approach imposes an axial component for the gas phase velocity as a function of distance from the nozzle, which is used in the droplet acceleration equation given by

$$
\frac{d U}{d t}=\frac{3}{8} C_{D} \frac{\rho_{g}}{\rho_{l} r_{d}}\left|U-V_{g a s}\right|\left(U-V_{g a s}\right),
$$

where $U$ is the droplet velocity vector, $C_{D}$ is the droplet drag coefficient, which is a function of Reynolds number, $\rho_{g}$ and $\rho_{l}$ are the gas and liquid phase densities, respectively, $r_{d}$ is the droplet radius, and $V_{g a s}$ is the gas phase velocity vector given as $V_{\text {gas }}=\left(V_{x}, V_{y}, V_{z}\right)$. The velocity components perpendicular to the spray axis (i.e., $V_{y}$ and $V_{z}$ ) are obtained from the Eulerian gas phase solution and $V_{x}$, the axial component of the gas phase velocity, is found from gas-jet theory as 


$$
V_{x}=\min \left[U_{i n j}, \frac{3 U_{i n j} d_{n o z} \sqrt{\frac{\rho_{l}}{\rho_{g}}}}{K_{\text {entr }} x}\left(\frac{1}{\left(1+\frac{12 r^{2}}{K_{\text {entr }}^{2} x^{2}}\right)^{2}}\right)\right],
$$

where $U_{i n j}$ is the injection velocity, Dnoz is the nozzle diameter, $K_{e n t r}$ is a model constant taken to be 0.7 as suggested by Abani et al. [24], $x$ is the position downstream of the nozzle on the spray axis, and $r$ is the radial position.

Droplet breakup is modeled using the hybrid Kelvin Helmholtz (KH) - Rayleigh Taylor (RT) model described by Beale and Reitz [22]. The droplet collision model is based on O'Rourke's model; however, a radius of influence method is used to determine the possible collision partners to further reduce mesh dependency [31]. In addition, the collision model was expanded by Munnannur [31] to include a more comprehensive range of collision outcomes. The current implementation of the droplet collision model considers the effects of bounce, coalescence, and fragmenting and nonfragmenting separations. Droplet interactions with the wall are considered through a wall film submodel [32], which includes the effects associated with splash, film spreading, and motion due to inertia.

\subsubsection{Model validation}

Direct experimental validation of the engine operating on DME was not available. For that reason the initial validation of the model was performed with experimental data of the engine fueled with diesel fuel, see Allen [20]. Then, DME fueled simulation were performed to validate the capability of the model to capture the differences between diesel and DME combustion characteristics. The justification behind this approach is that the DME chemical model has been validated [33] and it is expected that a mixing controlled combustion regime will be used. Accordingly, the CFD validation presented here addresses validation of the mixing characteristics.

Prior to the validation, a grid convergence study was performed. The results of the simulations were presented in the previous part of this study [34] and proved that the results were mesh independent for cell size under $3 \mathrm{~mm}$. The simulations with the final setup and $2 \mathrm{~mm}$ cell size had an average cell count of 32,000 cells and each case took an average of $20 \mathrm{~h}$ to complete. 


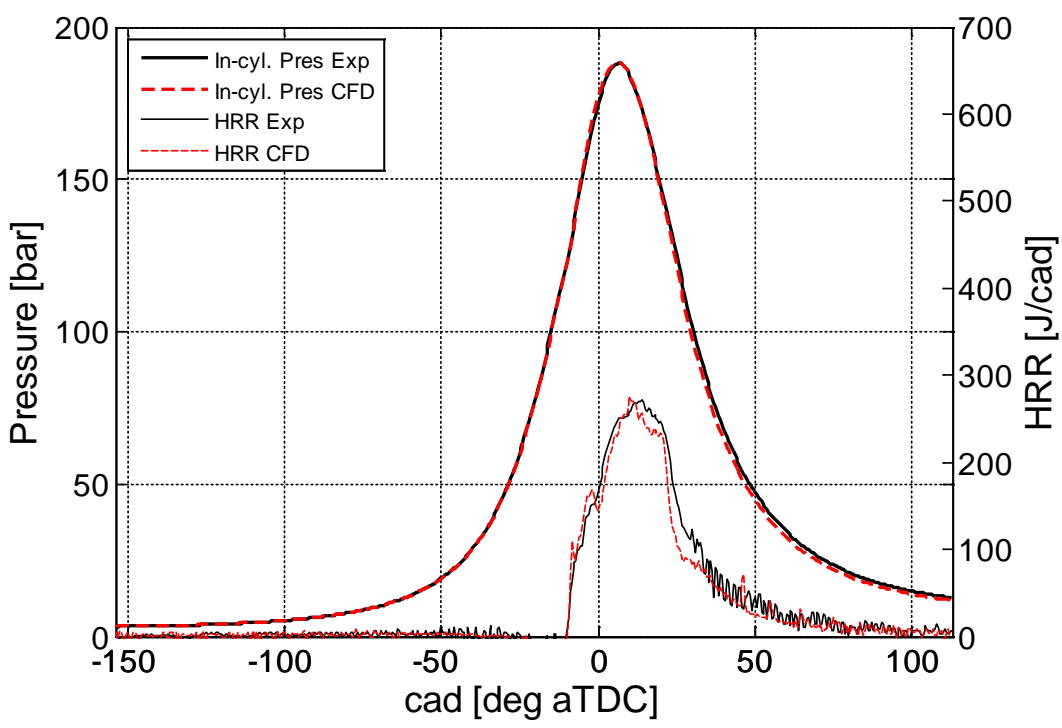

Figure 1 - Comparison of cylinder pressure and heat release rate (HRR) between CFD and experiments for the baseline case.

Figure 1 shows the comparison between the experimental and CFD in-cylinder pressure (Pcyl) and heat release rate profiles (HRR). A slight under-prediction in cylinder pressure and HRR is observed; however, overall the agreement between the CFD and the experiments is deemed acceptable. Table 3 shows the measured and predicted NIE, maximum pressure rise rate, NOx emissions, and peak pressure for the reference engine with various start of injection (SOI) timings. The maximum pressure rise rate and peak pressure are captured accurately. NIE is slightly under predicted and NOx emissions are slightly over predicted; however, all variables of interest show trend wise agreement with the measurements. Accordingly, the results are considered suitable for the present study.

Table 3 - Comparison of the selected key parameters between experiments and CFD results with diesel fuel.

\begin{tabular}{|c|c|c|c|c|c|}
\hline \multicolumn{2}{|c|}{ Case } & NIE & maxPRR & NOx & PP \\
\cline { 3 - 6 } \multicolumn{2}{|c|}{} & {$[\%]$} & {$[$ bar/deg] } & {$[\mathrm{g} / \mathrm{kWh}]$} & {$[\mathrm{bar}]$} \\
\hline \multirow{2}{*}{$\begin{array}{c}\text { SOI } \\
-13 \mathrm{cad}\end{array}$} & Exp & 44.43 & 5.88 & 2.9 & 188.12 \\
\cline { 2 - 6 } & Diesel CFD & 42.48 & 6.19 & 3.28 & 188.16 \\
\hline \multirow{2}{*}{$\begin{array}{c}\text { SOI } \\
-10 \mathrm{cad}\end{array}$} & Exp & 43.31 & 4.72 & 2.05 & 173.27 \\
\cline { 2 - 6 } & Diesel CFD & 42.37 & 5.16 & 2.58 & 174.2 \\
\hline \multirow{2}{*}{ SOI } & Exp & 42.3 & 4.7 & 1.66 & 164.75 \\
\cline { 2 - 6 }$-8 \mathrm{cad}$ & Diesel CFD & 42.37 & 4.71 & 2.13 & 166.95 \\
\hline
\end{tabular}


Once the CFD model was validated against experiments of the reference engine fueled with diesel, the exact same setup was then applied to the reference engine fueled with DME. In order to keep the amount of injected energy, injection duration and injection pressure constant, the injector nozzle hole diameter was adjusted from the diesel fueled value of $214 \mu \mathrm{m}$ to $300 \mu \mathrm{m}$ to match the diesel case when injecting DME. Figure 2 shows the in-cylinder pressure and HRR results with diesel fuel and DME and Table 4 shows the emissions and performance characteristics.

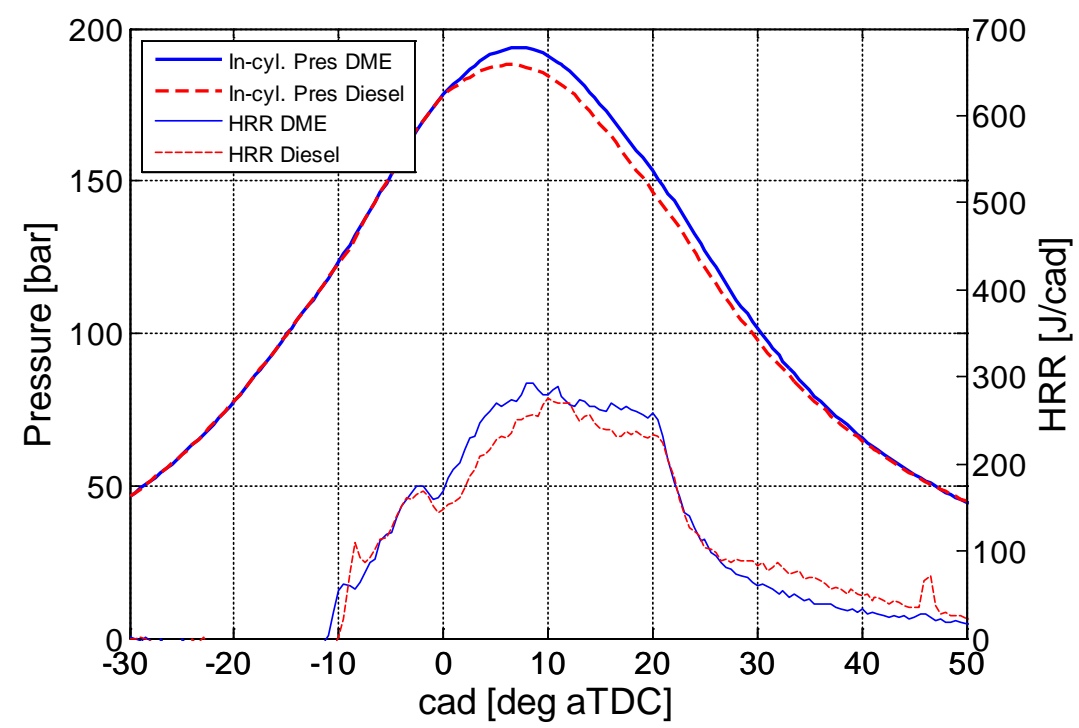

Figure 2 - CFD results of cylinder pressure and HRR using diesel and DME as fuels.

The differences between diesel and DME CFD results are consistent with the information found in the literature and discussed in the introduction section. That is, DME shows a faster heat release rate, resulting in an increase in peak pressure and NIE. The increased peak pressure and NIE are a result of the shorter ignition delay and improved mixing of DME. In terms of emissions, NOx emissions are lower for DME due to its lower adiabatic flame temperature. Since soot emissions from a DME fueled combustion system are expected to be negligible [15], soot was not considered in the validation process. 
Computational Optimization of the Combustion System of a Heavy Duty Direct Injection Diesel Engine Operating with Dimetyl-Ether

Table 4 - Comparison of the predicted parameters and performance between diesel and DME fueled engines.

\begin{tabular}{|c|c|c|c|c|c|}
\hline \multirow{2}{*}{\multicolumn{2}{|c|}{ Case }} & NIE & $\operatorname{maxPRR}$ & NOx & PP \\
\hline & & [\%] & [bar/deg] & [g/kWh] & [bar] \\
\hline \multirow{2}{*}{ SOI -13 } & Diesel CFD & 42.48 & 6.19 & 3.28 & 188.16 \\
\hline & DME CFD & 42.82 & 6.14 & 2.81 & 193.88 \\
\hline \multirow{2}{*}{ SOI -10 } & Diesel CFD & 42.37 & 5.16 & 2.58 & 174.2 \\
\hline & DME CFD & 42.55 & 5.13 & 2.1 & 177.72 \\
\hline \multirow{2}{*}{ SOI -8 } & Diesel CFD & 42.37 & 4.71 & 2.13 & 166.95 \\
\hline & DME CFD & 42.38 & 4.71 & 1.74 & 168.85 \\
\hline
\end{tabular}

\subsection{Computational Optimization Details}

\subsubsection{Genetic algorithm}

In this investigation, the optimization was carried out using an in-house developed genetic algorithm (GA) - a search technique inspired by the theory of evolution. A full description of the GA can be found in Klos [35]. The algorithm workflow is described in the 7 steps outlined below.

1. Select the best designs to be the parents for the next generation. For the first generation the parents are the initial conditions provided by the user.

2. Crossbreed the parents using the Punnett square technique (discussed below) to create a new generation.

3. Mutate each chromosome of each child in the generation.

4. Test the population against a fitness function

5. Penalize children that surpass the constraints.

6. Sort the population from highest to lowest.

7. Repeat from step one until the maximum number of generations are complete.

In the present GA, the mating selection is performed by using a Punnett square where the top $n$ designs from the previous generations become the parents of the new generation and each have a child with each other parent twice and themselves once producing a new generation of $n^{2}$ children. After the new generation is created, each variable of each child is then mutated. A normally distributed random number with its mean set to the current value and standard deviation set by the decaying time constant is 
generated and adds mutations to the system. As the GA progresses the time constant that dictates the mutation rate exponentially decays through

$$
\tau_{G A, i}=\tau_{G A, 0} * \exp \left(-\sigma_{G A} \frac{i}{n_{\text {end }}}\right),
$$

where $\tau_{G A, i}$ is the time constant at the $i^{\text {th }}$ generation, $\tau_{G A, 0}$ is the user specified initial time constant, $\sigma_{G A}$ is the standard deviation, $n_{\text {end }}$ is the user specified total number of generations.

\subsubsection{Piston bowl geometry and injection rate shape models}

An in-house code, capable of generating an arbitrarily shaped axisymmetric piston bowl geometry and automatically producing a block structured mesh suitable for KIVA$3 \mathrm{v}$ was developed. Although a full description can be found in [34], a brief description is provided here for completeness. The code generates the new piston shape using 5 control points and 10 shape parameters to generate Bezier curves describing the piston bowl profile. Figure 2 shows an example of the 15 parameters on a generic re-entrant style piston bowl. To maintain constant compression ratio as the bowl volume changes, the code adjusts the clearance height.

To facilitate analysis, the 15 parameters are combined into 3 geometric parameters during post-processing: bowl width, bowl depth and K. Using the nomenclature shown in Figure 3, bowl width is defined as G2+G3-G5+G7, bowl depth is defined as G4+G6+G8 and the reentrant parameter $\mathrm{K}$ is defined as G5, being positive for reentrant shapes, zero for a straight piston, and negative for an open geometry. 


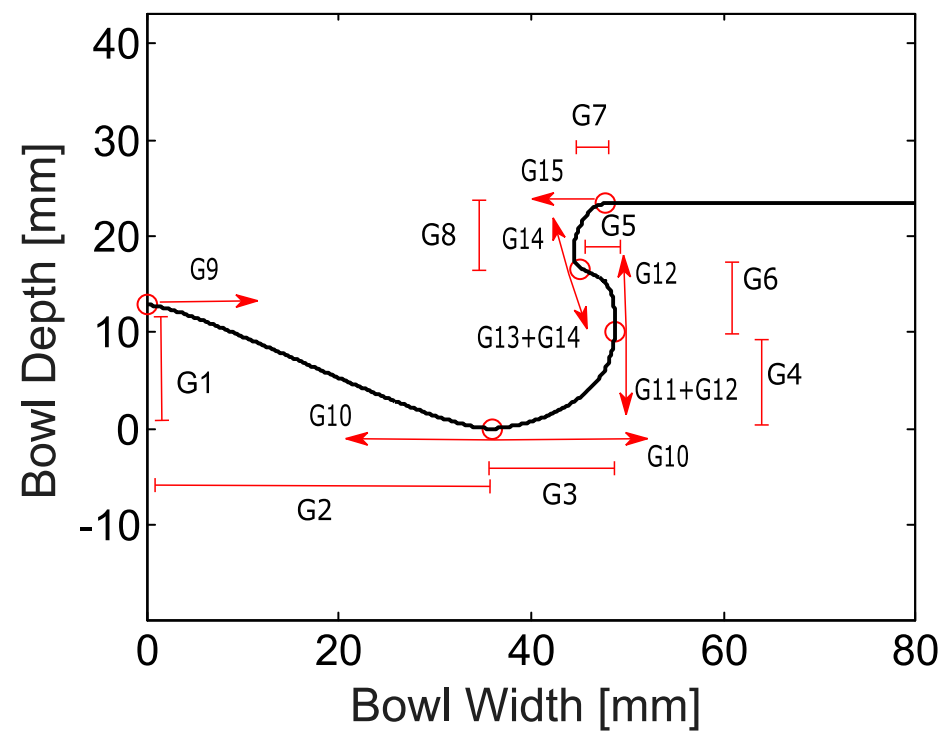

Figure 3 - Optimization parameters related to Bezier geometric points used in the geometry tool.

\subsubsection{Pumping work model}

An in-house code is used to calculate the pumping work needed to achieve the required intake boost to calculate the net indicated work. It is important to take into account the pumping work because DME fuel has a lower stoichiometric air/fuel ratio compared to diesel fuel, which represents a clear advantage in terms of pumping work. Additionally, stoichiometric operation requires substantially lower airflow than lean operation, accordingly, a pumping advantage is expected. The model is based on basic thermodynamic calculations supported by the hypothesis marked below.

1) Compressor and turbine work are considered equal so no mechanical losses are taken into account.

2) The compressor and turbine efficiencies are considered constant.

3) A constant pressure drop is considered between the compressor and the engine intake valve to simulate the effect of the aftercooler.

The target of this study is to optimize the engine and not the turbocharger. Accordingly, it assumed that, for every case simulated in this paper, the turbocharger has been chosen to have a compressor and turbine efficiency of $70 \%$ and $80 \%$, respectively. The aftercooler pressure drop is set to 0.15 bar. This approach has been previously used in other studies with successful results [36]. 


\subsubsection{Optimization Parameters and Setup}

The optimization focuses on maximizing NIE while keeping peak pressure (PP) and the maximum pressure rise rate (maxPRR) under 200 bar and 15 bar/deg., respectively. These values were selected to be comparable to a modern heavy duty engine operating at the rated power condition. A TWC with a NOx conversion efficiency of $99 \%$ is assumed. To meet a tailpipe NOx target of $0.0268 \mathrm{~g} / \mathrm{kW}-\mathrm{hr}$ [37], an engine out NOx constraint of $2.68 \mathrm{~g} / \mathrm{kWh}$ was applied.

A total of 21 input parameters are optimized. The input parameters are divided into 15 geometric parameters needed to describe the piston bowl shape and 6 important injection and air management settings. The geometric parameters are chosen as the minimum set of geometric parameters that gives enough freedom to the geometry tool to be able to generate geometries from bathtub to reentrant shape without penalizing the flexibility and smoothness of the designs. The 6 injection and air management settings are the start of injection (SOI) timing, exhaust gas recirculation (EGR), swirl, nozzle hole diameter (Dnoz), nozzle angle (NA) and injection pressure (IP). The pressure at IVC (PIVC) is adjusted with the EGR level to maintain stoichiometric operation. The values of PIVC needed to keep a stoichiometric equivalence ratio for each EGR value are shown in Figure 4.

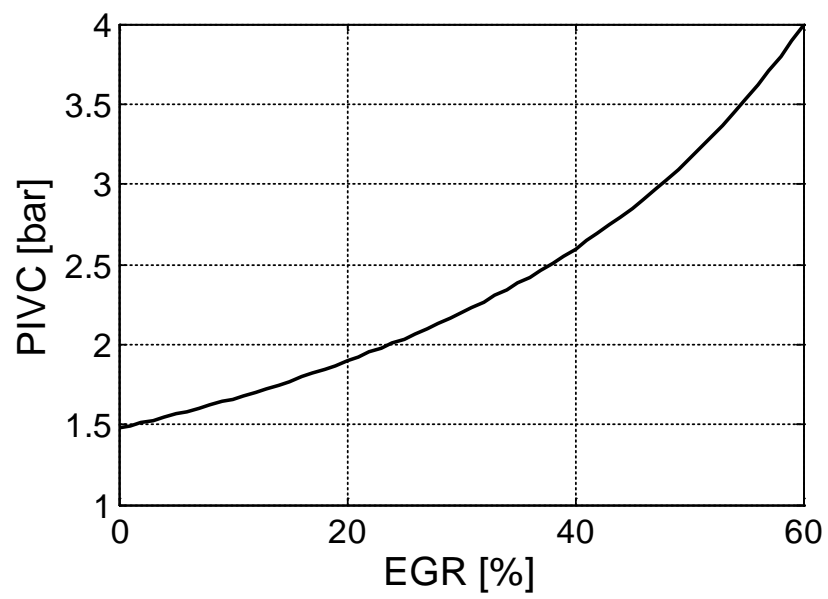

Figure 4 - Pressure at intake valve closure (PIVC) needed to achieve a stoichiometric equivalence ratio.

Table 5 shows the ranges of design parameters considered. The parameter ranges were chosen to span the design space relevant to current and future technology. 
Table 5 - Ranges used for the optimization inputs.

\begin{tabular}{|l|c|c|c|c|c|c|c|c|c|}
\hline & G1 - G4 & G5 & G6 - G15 & Dnoz & NA & SOI & IP & EGR & Swirl \\
\hline & {$[-]$} & {$[-]$} & {$[-]$} & {$[\mu \mathrm{m}]$} & {$[\mathrm{deg}]$} & {$[\mathrm{cad}]$} & {$[\mathrm{bar}]$} & {$[\%]$} & {$[-]$} \\
\hline Min. & 0.01 & -0.99 & 0.01 & 200 & 45 & -35 & 500 & 2 & 0.1 \\
\hline Max & 0.99 & 0.99 & 0.99 & 350 & 90 & 5 & 2600 & 62 & 3 \\
\hline
\end{tabular}

The optimization uses a population size of 529 cases per generation and was run for 40 generations, resulting in a total of 21,160 function evaluations. The number of function evaluations and generations was based on other similar optimizations carried out prior to this study and the results will show the optimization resulted in a converged solution.

To analyze the effects of each optimization parameter, the Component Selection and Smoothing Operator (COSSO) method [38] was used to fit a response surface to the outputs as a function of each input. The non-parametric fitting method showed an average correlation coefficient $\left(R^{2}\right)$ of 0.98 , assuring an accurate fit.

\section{Results and Discussion}

This section presents the optimization results, compares the optimized solution to a baseline case, and discusses the most relevant cause-effect relations between the optimized inputs and outputs.

\subsection{Optimization results}

The optimum was found after 40 generations and the NIE converged to a value of $43.4 \%$ as seen in Figure 5. The set of optimum values for the input parameters are shown in Table 6. 
Computational Optimization of the Combustion System of a Heavy Duty Direct Injection Diesel Engine Operating with Dimetyl-Ether

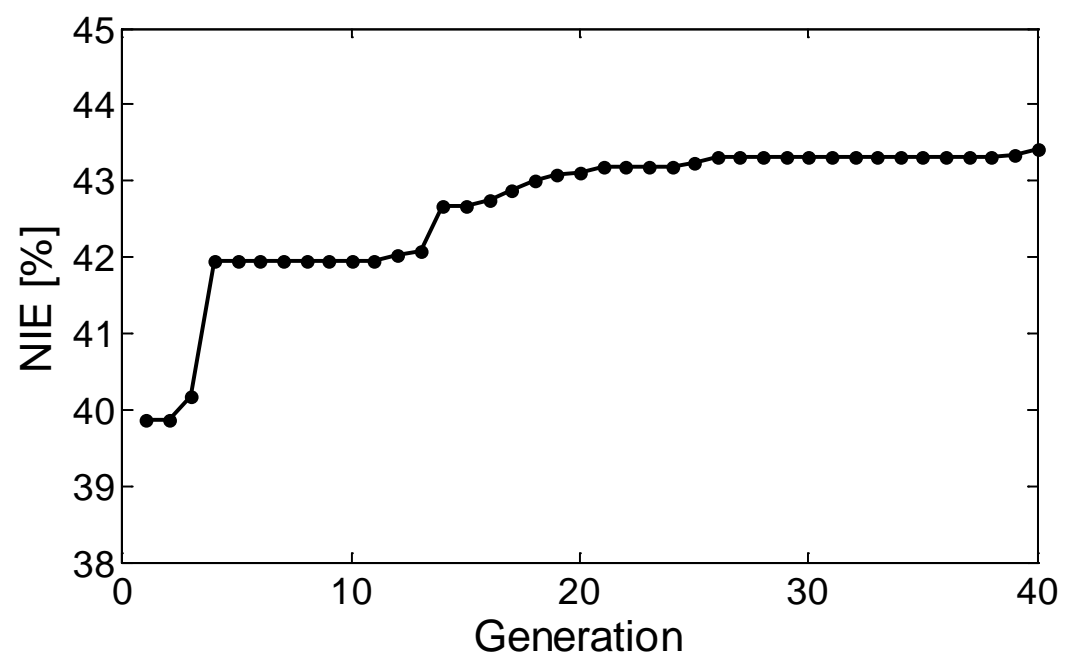

Figure 5 - Optimum NIE value for each generation.

Table 6 - Optimum values for the 21 inputs optimized (top) geometric inputs, (bottom) injection and air management settings.

\begin{tabular}{|c|c|c|c|c|c|c|c|c|c|c|c|c|c|c|}
\hline G1 & G2 & G3 & G4 & G5 & G6 & G7 & G8 & G9 & G10 & G11 & G12 & G13 & G14 & G15 \\
\hline$[-]$ & {$[-]$} & {$[-]$} & {$[-]$} & {$[-]$} & {$[-]$} & {$[-]$} & {$[-]$} & {$[-]$} & {$[-]$} & {$[-]$} & {$[-]$} & {$[-]$} & {$[-]$} & {$[-]$} \\
\hline 0.02 & 0.74 & 0.53 & 0.68 & 0.36 & 0.46 & 0.30 & 0.27 & 0.87 & 0.42 & 0.49 & 0.45 & 0.36 & 0.58 & 0.47 \\
\hline
\end{tabular}

\begin{tabular}{|c|c|c|c|c|c|}
\hline Dnoz & NA & SOI & IP & EGR & Swirl \\
\hline$[\mu \mathrm{m}]$ & {$[\mathrm{deg}]$} & {$[\mathrm{cad}]$} & {$[\mathrm{bar}]$} & {$[\%]$} & {$[-]$} \\
\hline 330 & 61.7 & -13.09 & 2594 & 33 & 2.98 \\
\hline
\end{tabular}

Figure 6 compares the optimum piston shape with the baseline geometry. The process shifted the reference piston geometry towards a non-reentrant shape. The optimum geometry is flat (i.e., the GA removed the pip) and shallower than the stock diesel bowl. The piston width is similar to the baseline engine. Additionally, the nozzle included angle was selected to be slightly narrower than the baseline geometry. 


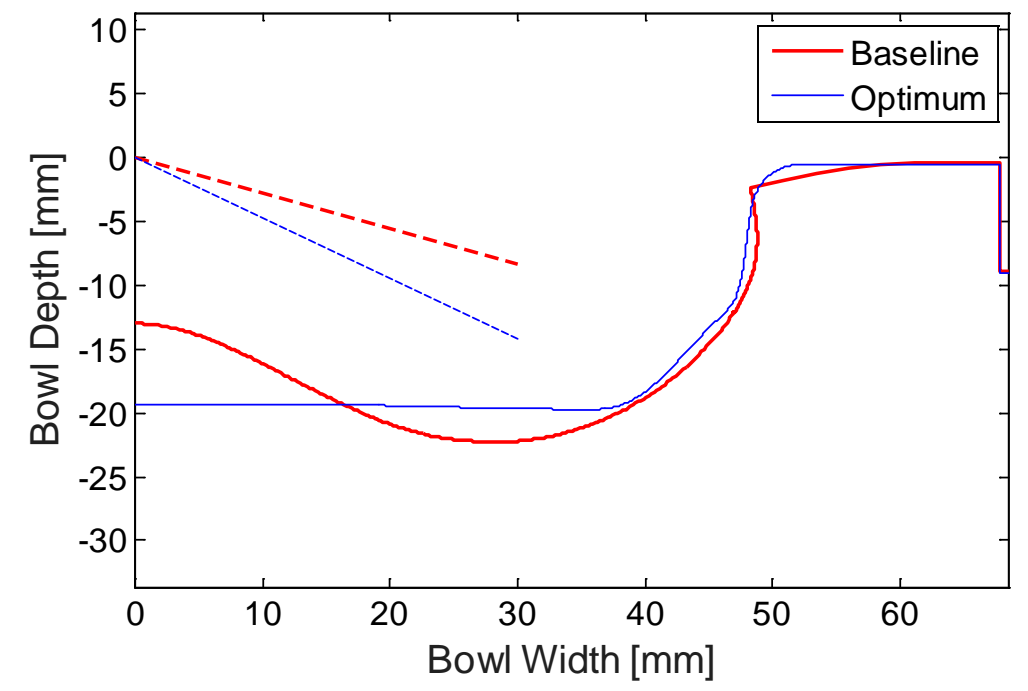

Figure 6 - Optimum and baseline case bowl geometry and nozzle angle configuration.

The results of the optimization in terms of the input variables are shown in Figure 7. As defined in the piston bowl geometry model section, the geometric inputs were combined into bowl width, bowl depth, and reentrant factor. Figure 7 shows broad coverage of the design space and convergence to the optimized solution. 

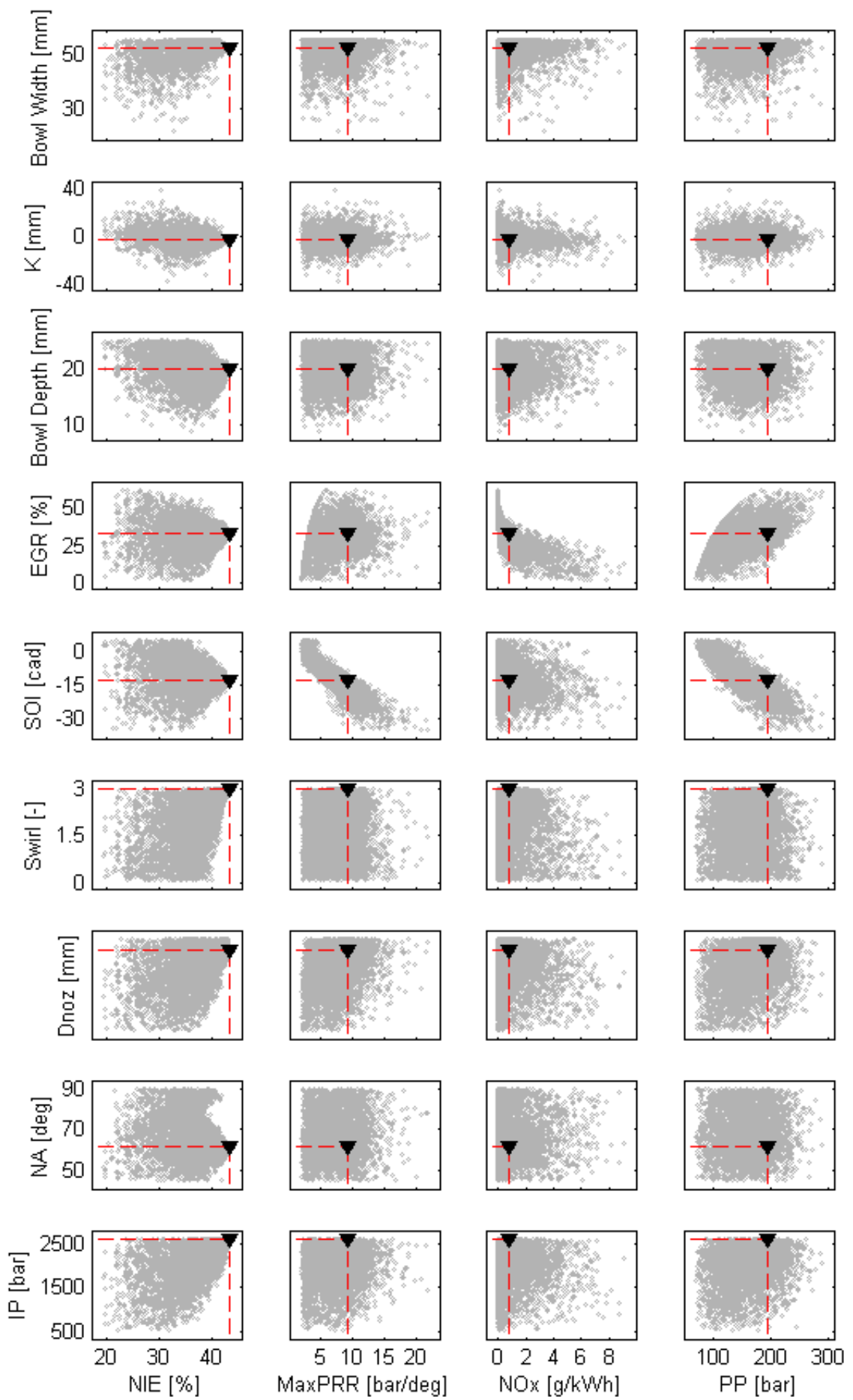

Figure 7 - Input versus output for all optimization cases. All data points are shown in grey circles and the optimum solution is shown by the black triangle.

To investigate the impact of the constraints, Figure 8 shows the optimization outputs plotted as functions of each other. These results confirm that the output space 
was adequately covered and, since the unconstrained peak NIE case corresponds to the current optimum configuration, show that reducing the constraints would not enable further increases in NIE. This is interesting because it suggests that the combustion system would be able to meet more stringent emissions regulations with minimal degradation of NIE.
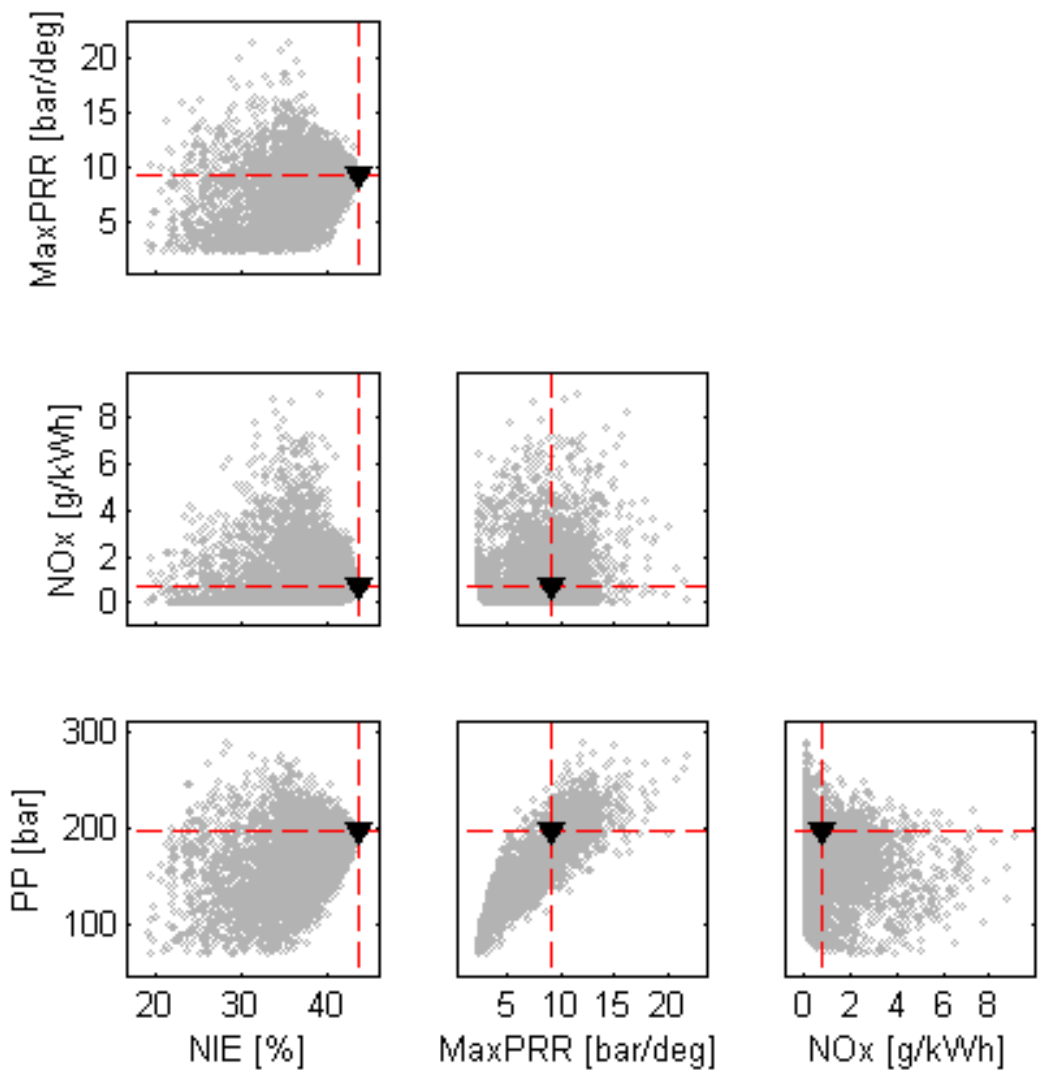

Figure 8 - Output versus output for all optimization cases. All data points are shown in grey circles and the optimum solution is shown by the black triangle.

Table 7 compares the efficiency and emissions of the optimum solution and the baseline case. The baseline case selected for comparison is the validation case with a SOI timing of -13 deg aTDC fueled with DME. This case was selected because it showed the best performance out of the cases used for validation.

Table 7 - Performance and emissions for the baseline and optimum cases.

\begin{tabular}{|c|c|c|c|c|}
\hline Case & NIE & maxPRR & NOx & PP \\
\hline & {$[\%]$} & {$[\mathrm{bar} / \mathrm{deg}]$} & {$[\mathrm{g} / \mathrm{kWh}]$} & {$[\mathrm{bar}]$} \\
\hline Baseline DME case & 42.8 & 6.1 & 2.81 & 194 \\
\hline Opt. case & 43.4 & 9.2 & 0.74 & 197 \\
\hline
\end{tabular}


The optimum configuration increased NIE from $42.8 \%$ to $43.4 \%$ and reduced the engine out NOx emissions from $2.81 \mathrm{~g} / \mathrm{kWh}$ to $0.74 \mathrm{~g} / \mathrm{kWh}$. Assuming a 99\% efficient TWC, the resulting tailpipe NOx would be $0.0074 \mathrm{~g} / \mathrm{kWh}$ (i.e., $72 \%$ below the proposed future NOx emissions targets of $0.0268 \mathrm{~g} / \mathrm{kWh}$ ). Additionally, the peak pressure rise rate and peak pressure were similar to the baseline values.

Table 8 - Energy balances for the baseline and optimum cases.

\begin{tabular}{|c|c|c|c|c|c|}
\hline Case & $\begin{array}{c}\text { Gross } \\
\text { Indicated work }\end{array}$ & $\begin{array}{c}\text { Heat } \\
\text { Transfer }\end{array}$ & Exhaust losses & Unburnt fuel & Pump. work \\
\hline & {$[\mathrm{J}]$} & {$[\mathrm{J}]$} & {$[\mathrm{J}]$} & {$[\mathrm{J}]$} & {$[\mathrm{J}]$} \\
\hline Baseline & 4854 & 1926 & 4215 & 268 & 31 \\
\hline Optimum & 4832 & 1991 & 4076 & 364 & -58 \\
\hline
\end{tabular}

Table 8 shows the energy balances of the baseline and optimum cases. It can be seen that the gross indicated work is very similar for both cases. The main advantage from the optimum case can be attached to the pumping work, that is able to compensate the slightly lower gross indicated work of the optimum case, leaving an overall increase in NIE of $0.6 \%$. This improvement in pumping work is due to the lower airflow needed to operate at stoichiometric conditions. That is, the DME case needs 0.94 bar less pressure at IVC, which reduces the pumping losses by $0.8 \%$ of the fuel energy. This effect can be seen in Figure 9 where there is a noticeable difference in the in-cylinder pressure profile.

In terms of HRR, Figure 9 shows that the optimum case is able to significantly shorten the combustion duration. This effect compensates the lower in-cylinder pressure at IVC of the DME case resulting in a slightly higher peak pressure than the baseline case. Even though the optimum case has a higher equivalence ratio and should mix slower, also seen in Table 8 where the unburned fuel mass is higher for the optimum, the optimum case is able to noticeably reduce the combustion duration compared to the reference case. 


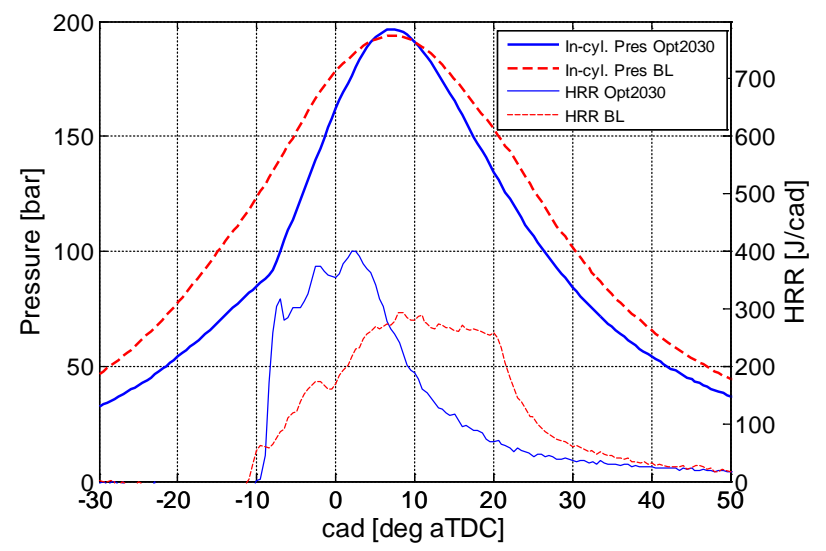

Figure 9 - Cylinder pressure and HRR for the baseline and the optimum cases.

Figure 10a shows the normalized fuel injection rate and normalized burned fuel mass. The optimum case, which keeps the same SOI as the baseline case, reaches both 90\% fuel mass injected and 90\% fuel burned earlier than the baseline case. However, since the injection rate is different, reaching the $90 \%$ fuel mixed mass earlier does not mean that the optimum case mixes better than the baseline case. To compare the mixing velocity for two cases with different injection profiles, Figure 10b shows the apparent combustion time (ACT) [39] [40]. ACT is defined as the time interval between the instant at which the percentage of the mass is injected and the instant at which the same percentage of fuel mass is burned, that is, shorter ACT means shorter mixing time. These results are of interest since they show that even though the combustion duration is shorter for the optimum case, the baseline case has a lower ACT for most of the combustion process, that is, it mixes better than the optimum. Then, as expected operating in stoichiometric conditions, the optimum case has difficulties mixing compared to the baseline case because there is less fresh air and in-cylinder gas density. As a direct consequence, to avoid the negative impact of the poor mixing performance of the combustion system on NIE, the optimum case is forced to compensate it by adjusting the injection settings in order to maintain a short combustion duration. 


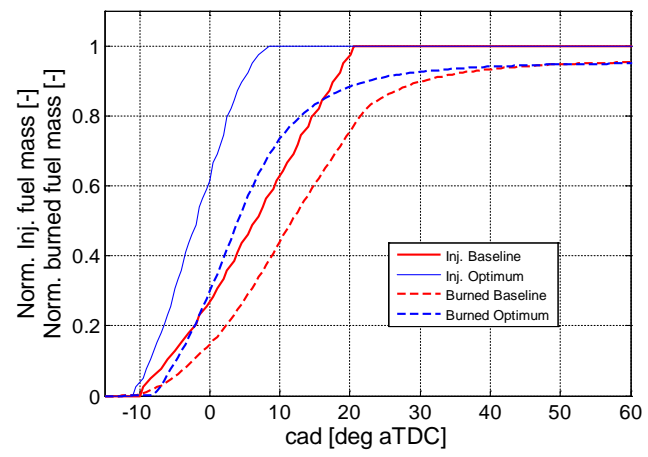

(a)

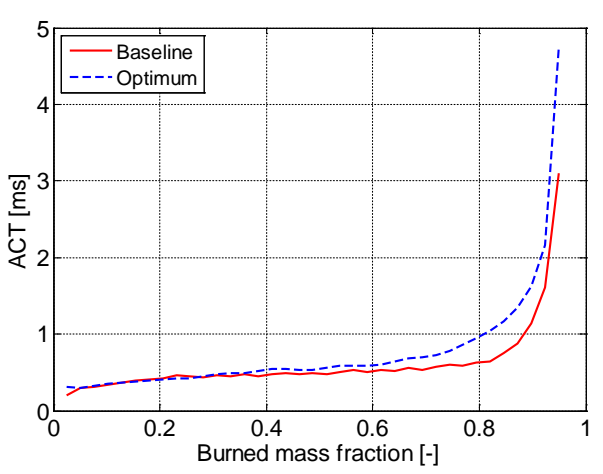

(b)

Figure 10 - (a) normalized injected fuel mass and normalized burned fuel mass and (b) apparent combustion time for the baseline and optimum cases.

Figure 11 shows the in-cylinder temperature and heat transfer losses. As expected, the stoichiometric optimum case shows higher average temperature than the baseline case. As a consequence, the total heat transfer through the combustion chamber walls increases by $\sim 3 \%$. It is interesting to note that, although the exhaust temperature of the optimum case is higher than the baseline case (see Table 8), the exhaust energy is higher for the baseline case. This is due to the lower trapped mass of the optimum case, which results in lower exhaust energy even with higher exhaust temperature.

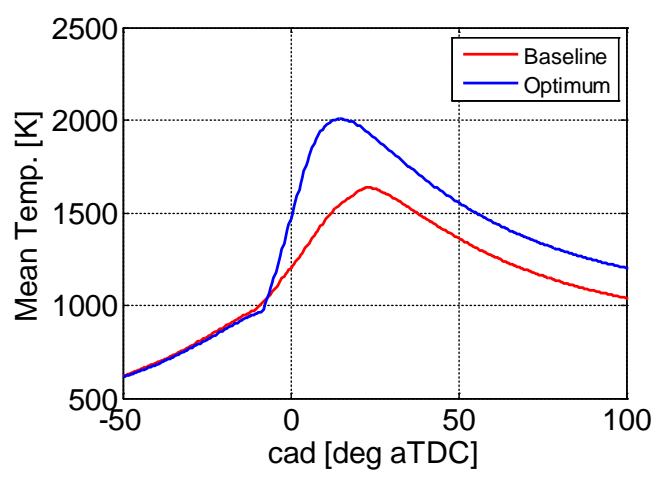

(a)

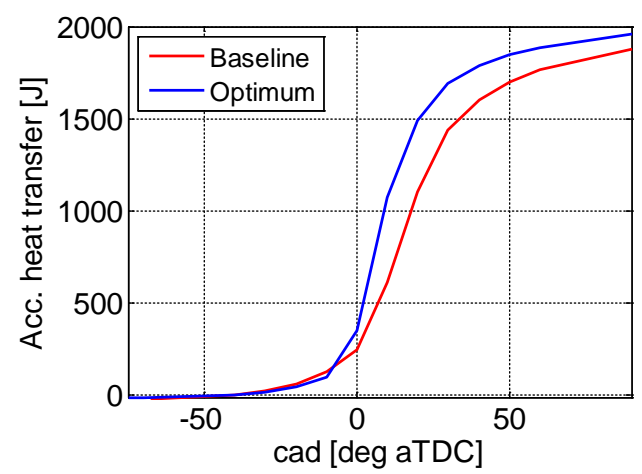

(b)

Figure 11 - (a) mean in-cylinder temperature and (b) accumulated heat transfer for the baseline and optimum cases.

Figure 12 shows the heat transfer rate. Initially, the heat transfer rate is higher for the optimum case, but by 10 deg aTDC, the situation switches and the heat transfer rate decreases to a value lower than that of the baseline case for the rest of the cycle. In order to understand the heat transfer characteristics, Figure 13 shows temperature distributions for the baseline and optimum cases. It can be seen that the in-cylinder 
temperature of the optimum case rapidly increases due to the shorter combustion process, explaining the higher initial heat transfer rate found in Figure 12. However, the increased mixing of the optimum case results in rapid homogenization of the gas temperature. That is, by 30 deg aTDC, the in-cylinder gas temperature distribution is relatively uniform for the optimum case; however, the lower mixing rate of the baseline case results in higher local temperatures near the cylinder liner and cylinder head. This results in relatively high heat transfer losses later in the cycle. In addition, the surface area of the optimized piston bowl is $29.7 \%$ smaller than that of the reference bowl (baseline bowl shape has a surface area of $4909 \mathrm{~mm}^{2}$ and optimum bowl shape has a surface area of $3451 \mathrm{~mm}^{2}$ ), which helps to reduce heat transfer losses during the whole cycle.

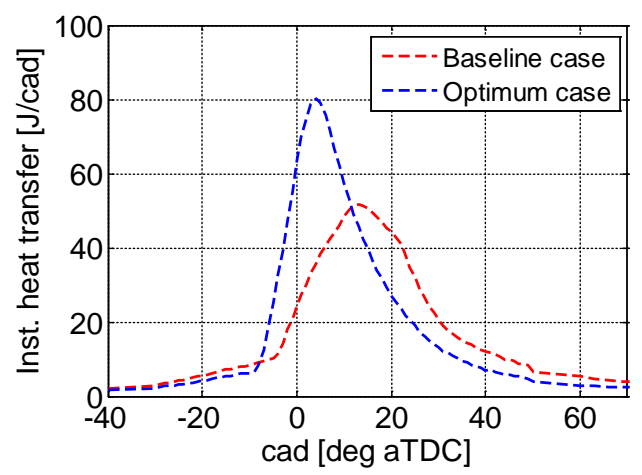

Figure 12 - Instantaneous heat transfer for the baseline and optimum cases.

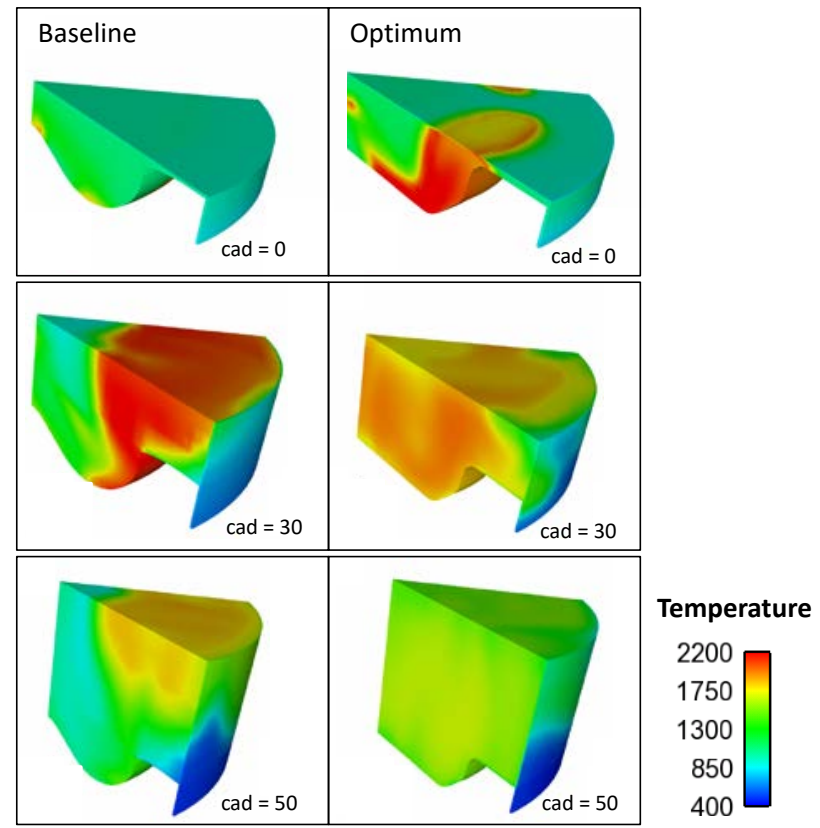

Figure 13 - In-cylinder temperature for (left column) the DME fueled baseline case and (right column) the optimum case. 


\subsection{Parametric Dependence}

To identify parametric dependencies, the results were analyzed using the nonparametric fitting method, COSSO, and the results for the most relevant inputs on the optimum configuration are presented. Figure 14 shows the impact of EGR, swirl ratio, injection pressure, and SOI timing on performance (NIE, heat transfer, combustion duration, combustion efficiency and peak pressure) and NOx emissions. Note that EGR, swirl ratio and injection pressure are plotted against SOI timing due to the strong impact of SOI timing on peak pressure and NIE.

All four parameters have a noticeable effect on NIE. Retarding SOI timing decreases combustion efficiency and increases the combustion duration, resulting in lower NIE. Similarly, retarding SOI timing shifts the combustion phasing towards the expansion stroke, decreasing the peak pressure, maximum mean temperature, peak temperature, and total heat transfer. Although delayed SOI timing reduces heat transfer, the effect is outweighed by the decrease in combustion efficiency and increase in combustion duration. The peak pressure restriction imposed in this optimization limits the advance of the SOI timing to -13.09 deg aTDC.

EGR is one of the most influential inputs in the optimization. It has an effect on NIE, but it is mainly used to control the NOx emissions. The results show that, when a stoichiometric mixture is maintained, the trade-off between NOx and NIE is removed and both parameters improve with increasing EGR. Higher EGR levels reduce the oxygen mole fraction, reducing the adiabatic flame temperature and decreasing NOx emissions and peak temperature. Additionally, at a fixed equivalence ratio, higher EGR levels increase the in-cylinder trapped mass and specific heat, further reducing the incylinder temperature and heat transfer losses. Conversely, since the oxygen concentration is reduced, lack of free oxygen results in slower combustion (increased burn duration) and lower combustion efficiency. Evidently, the reduced heat transfer losses outweigh the longer burn duration and lower combustion efficiency, resulting in a net increase in NIE with increased EGR.

Since the charge is stoichiometric, access to free oxygen is limited in the late stages of the combustion process. Increasing the swirl ratio allows the later injected fuel to access oxygen between the plumes, shortening the combustion duration, and increasing combustion efficiency. However, the higher swirl ratio also increases the in-cylinder 
velocities, which results in higher heat transfer losses. In contrast to the effect of EGR, where the reduced heat transfer losses outweighed the increase in burn duration, the shorter burn duration for increased swirl ratio outweighs the increased heat transfer. That is, NIE increases with increasing swirl ratio due to the trend of decreasing combustion duration with increasing swirl ratio.

The effect of injection pressure is similar to that of swirl ratio. That is, increasing injection pressure increases heat transfer, but also shortens combustion duration and increases combustion efficiency resulting in a NIE improvement. It is interesting to note that injection pressure and swirl ratio are complimentary. This shows the importance of the mixing process in stoichiometric direct injected engines. 
Computational Optimization of the Combustion System of a Heavy Duty Direct Injection Diesel Engine Operating with Dimetyl-Ether
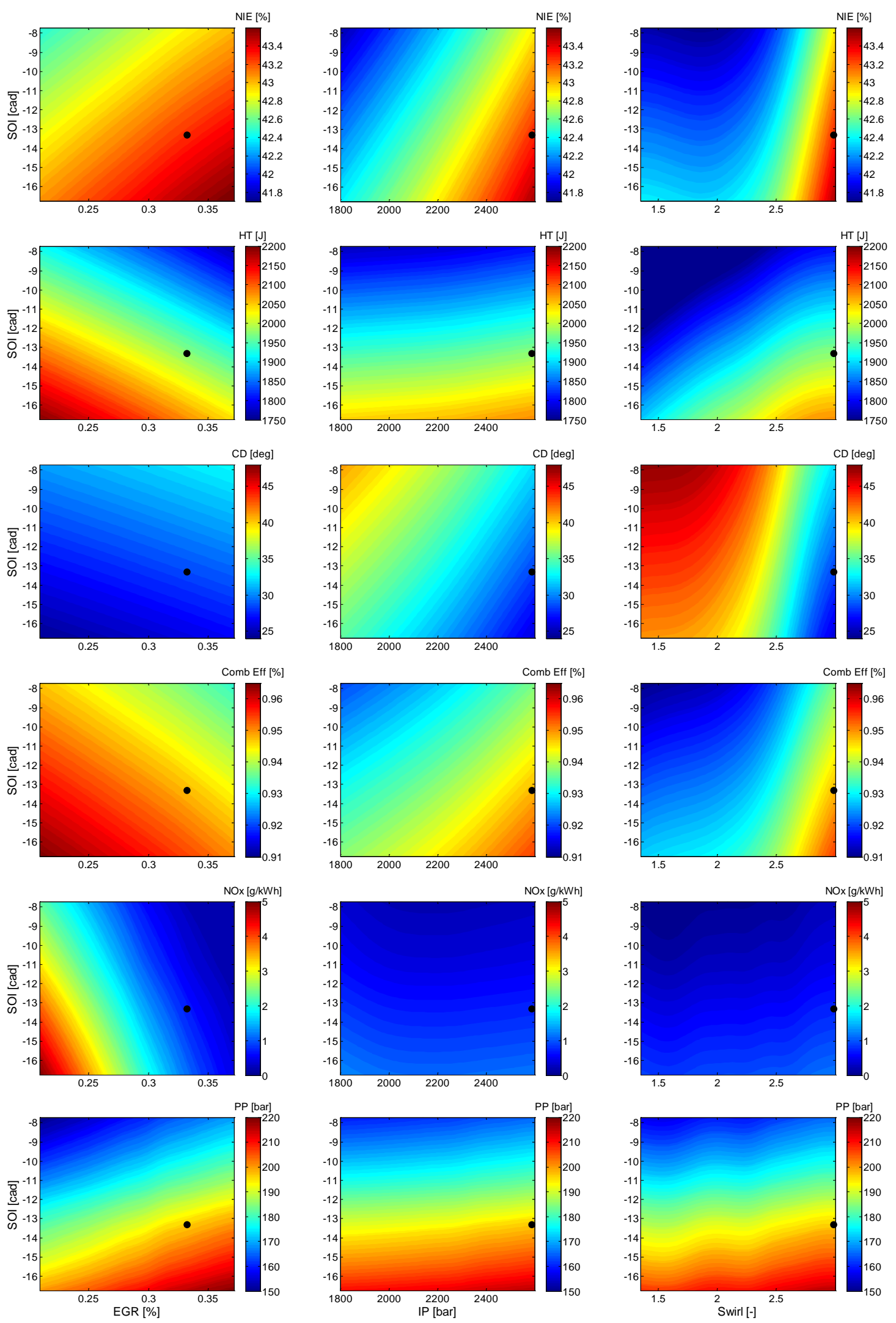

Figure 14 - Response surface of the coupled effect of EGR, IP, Swirl with SOI over NIE, heat transfer, combustion duration (CD), combustion efficiency, NOx and PP. The optimum value for every input is shown by the black dot. 
The main restrictions in this optimization are NOx emissions and peak pressure. It has been seen that EGR is able to control NOx and at the same time improve efficiency, breaking the NOx-NIE trade-off. However, peak pressure is not controllable while improving NIE and peak pressure can be reduced at the cost of increased combustion duration and reduced efficiency. It can also be seen that lower EGR ratios could solve the peak pressure problem. That is, because the required intake pressure decreases with decreasing EGR, the peak pressure also decreases with decreasing EGR. However, SOI timing has a stronger effect on peak pressure than EGR. Accordingly, SOI timing was used to control peak pressure.

\subsection{Parameter Evolution}

After the comparison of the optimum and the baseline case and the isolated effects of the most relevant inputs on the engine performance are understood, it is easier to understand the optimum combustion system. The process shifted the reference piston shape towards a flatter, shallower bowl than the baseline geometry to reduce the surface area to offset the increased heat transfer associated with high injection pressure and high swirl. The geometry is non-reentrant and has a rounded bowl rim to allow access to oxygen in the squish region. Similar to the bowl geometry, the injector geometry is adjusted to have the best interaction possible with the optimum piston geometry and improve mixing. Then the swirl ratio, injection pressure and nozzle hole diameter are needed to shorten the combustion duration and increase efficiency. EGR is used to control the NOx emissions, but since adding EGR also increases NIE due to reduced heat transfer, the final EGR levels are higher than the necessary levels to control NOx emissions. Finally, SOI is used to adjust peak pressure.

To illustrate the evolution of the combustion system, CFD simulations were repeated at various key points during the design evolution. Figure 15 shows the results of this investigation. First, a stoichiometric DME case was run with all of the baseline parameters. The only change from the lean DME fueled case was that the intake pressure was reduced to 2.06 bar to achieve stoichiometric operation. This resulted in a significant increase in incomplete combustion due to the difficulty accessing free oxygen. The heat transfer reduces slightly due to the lower combustion efficiency. The result is a reduction in GIE from the baseline value of $42.8 \%$ to $35.6 \%$. This shows that replacing a conventional diesel combustion system with a stoichiometric DME 
combustion system with no other changes would result in poor performance. That is, the system must be re-optimized to enable peak performance. Next, the case was repeated with the optimum piston bowl geometry. This caused a reduction in heat transfer due to the lower surface area to volume ratio and resulted in a marginal increase in GIE from $35.6 \%$ to $35.8 \%$. Notice that most of the reduced heat transfer losses end up as exhaust energy rather than increased work. It is also interesting to note that the combustion efficiency was approximately constant when the piston bowl was changed from the baseline case to the optimum bowl geometry. Next, the case was repeated by changing the nozzle included angle from the baseline value of $65^{\circ}$ to the optimum value of $61.7^{\circ}$. This caused an increase in GIE from $35.8 \%$ to $37.3 \%$ due to reduced incomplete combustion resulting from improved oxygen utilization. Note that the heat transfer and exhaust losses are nearly unchanged. Next, the case was repeated with the optimum injection pressure (i.e., the injection pressure was increased from the baseline value of 1800 bar to the optimum value of 2594 bar). This caused a further improvement in the mixing process, increasing the GIE from $37.3 \%$ to $40.9 \%$. The increase in GIE is due to reduced incomplete combustion and a shorter burn duration (i.e., reduced exhaust losses) and suggest that DME fuel system development efforts should focus on enabling high pressure operation. Notice that heat transfer increases back to a value nearly the same as the baseline lean case. This shows the importance of the reduced heat transfer losses resulting from the improved piston bowl geometry. That is, although the addition of the piston bowl alone does not directly improve efficiency, it reduces heat transfer and allows higher injection pressure to be used to improve efficiency. Next, the case was repeated with the optimum nozzle hole diameter (i.e., the nozzle diameter was increased from $300 \mu \mathrm{m}$ to $330 \mu \mathrm{m}$ ). This caused a slight increase in heat transfer and reduced the GIE from $40.9 \%$ to $40.7 \%$. This suggests that the nozzle hole diameter has a minimal influence on the efficiency. This makes sense for a stoichiometric combustion system, as the fuel needs to both be introduced into the combustion chamber and be able to find free oxygen. The increased nozzle diameter addresses the fuel introduction, but does not improve access to oxygen. Next, the case was repeated with the optimum EGR (i.e., the EGR was increased from $25 \%$ to 33\%). This caused a slight reduction in heat transfer due to the increased in-cylinder mass and lower temperature, increasing GIE from $40.7 \%$ to $40.9 \%$. Next, the case was repeated with the 
optimum swirl ratio (i.e., the swirl ratio was increased from 0.7 to 2.98 ). This caused a noticeable improvement in the mixing process, reducing the incomplete combustion, and increasing the GIE from $40.9 \%$ to $43.2 \%$. In terms of heat transfer, it is unchanged when increasing swirl from the baseline value (0.7) to the optimum value (3), contrary to Figure 14. This happens because the baseline swirl is out of the range shown in Figure 14 and the behavior of heat transfer in terms of swirl changes for very low swirl. Finally, the next case is the optimum case after adding the optimum SOI. This caused almost no effect since the optimum SOI and the baseline SOI are almost identical, but the trends presented are consistent with the small GIE increase with advanced SOI.

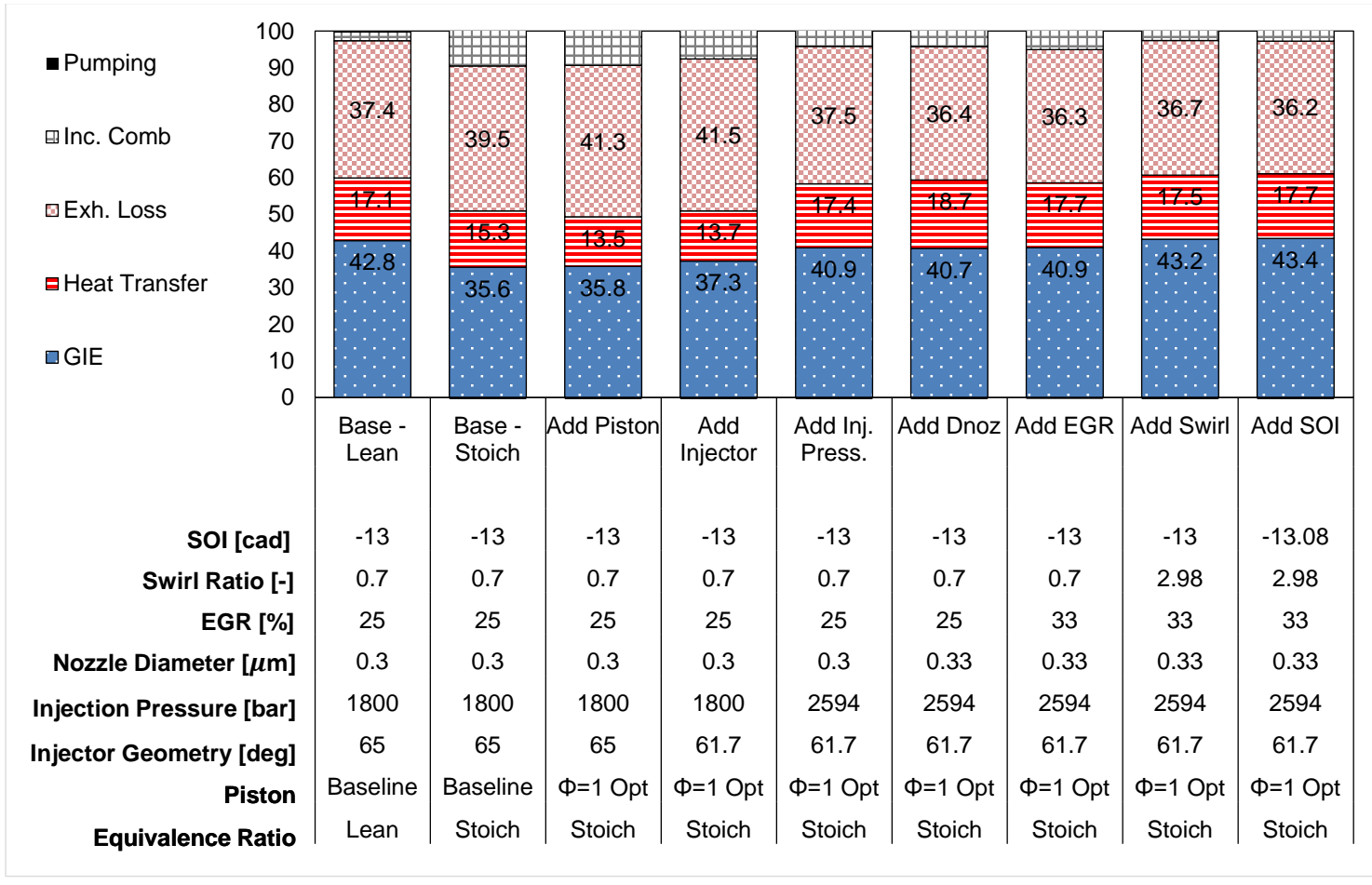

Figure 15 - Evolution of the optimum stoichiometric DME fueled combustion system.

\section{Conclusions}

A genetic algorithm based optimization coupled with CFD has been applied to a heavy-duty engine fueled with DME working under stoichiometric conditions. The optimization considered 21 input variables (15 geometric, 4 injection settings and 2 air management settings). The final optimum configuration improved NIE by $0.6 \%$ while enabling the use of a three way catalyst for NOx reduction. Considering a 99\% efficient 
three way catalyst, the tailpipe NOx levels would be $0.0074 \mathrm{~g} / \mathrm{kWh}$. That is, the proposed solution shows the potential to meet future NOx regulations while maintaining diesel-like thermal efficiency.

The new combustion system resulted in a shallow, non-reentrant piston with a flat center (i.e., the central protrusion was removed). The nozzle included angle of $61.7^{\circ}$ was selected to enable access to oxygen throughout the combustion chamber. The EGR was set to a value of 33\% with high injection pressure (2594 bar), high swirl ratio (2.98), early SOI timing (-13.09 deg aTDC), and a large nozzle hole diameter $(0.33 \mathrm{~mm})$. This optimum coincides with the unconstrained peak NIE case because the restriction of controlling NOx emissions is easily achievable by a stoichiometric combustion system coupled with a three way catalyst, removing the trade-off between NIE and NOx.

Heat transfer and mixing were proven to be the main challenges of the new combustion system. This is because the configuration operates under stoichiometric conditions, resulting in high bulk gas temperature and limited access to free oxygen. The optimum geometry was adapted to reduce surface area in order to reduce heat transfer and the high injection pressure and swirl improved the mixing process. The sensitivity of the input variables was analyzed using non-parametric fitting methods to identify the key optimization parameters. EGR was the main parameter used to control NOx emissions. Contrary to conventional mixing controlled combustion, it was found that increasing EGR also increased NIE due to reduced heat transfer loss. Swirl, nozzle hole diameter, and injection pressure had the potential to improve combustion duration and efficiency with a small effect on NOx and peak pressure. Finally, SOI showed a significant effect over peak pressure and was used to keep the peak pressure under the limits with a degradation of the combustion duration and efficiency that was compensated with higher swirl and injection pressure levels.

The results presented in this paper show that a stoichiometric DME fueled combustion system coupled with a three way catalyst has potential to be used for future generation compression ignition engines. The non-sooting nature of DME together with the capability of the three way catalyst to control NOx permits the new combustion system to completely manage NOx and soot emissions while maintaining diesel-like efficiency. The present study encourages future research work in the frame of DME fueled engines. 


\section{Acknowledgments}

Authors acknowledge that this work was possible thanks to the Ayuda para la Formación de Profesorado Universitario (FPU 13/02817) belonging to the Subprogramas de Formación y de Movilidad del Ministerio de Educación, Cultura y Deporte from Spain.

\section{References}

[1] L. Lázaro, C. Aparecida and P. Lacava, "Strategies for emission control in diesel engine to meet Euro VI," Fuel, no. 104, pp. 183-193, 2013.

[2] B. Miller, Fossil Fuel Emissions Control Technologies, Butterworth Heinemann, 2015.

[3] J. Thangaraja and C. Kannan, "Effect of exhaust gas recirculation on advanced diesel combustion and alternate fuels : A review," Applied Energy, vol. 180, pp. 169-184, 2016.

[4] M. Khair, "Technical and synergistic approaches towards the 21st century," SAE technical paper, no. 972687, 1997.

[5] C. Digiulio, J. Pihl, J. Choi, J. Parks, M. Lance, T. Toops and M. Amiridis, "Effects of lean/rich cycle timing and temperature," Applied Catalysis B: Environmental, vol. 147, pp. 698-710, 2014.

[6] S. Prabhu, N. Nayak, N. Kapilan and V. Hindasageri, "An experimental and numerical study on effects of exhaust gas temperature and flow rate on deposit formation in Urea-Selective Catalytic Reduction (SCR) system of modern automobiles," Applied Thermal Engineering, vol. 111, pp. 1211-1231, 2017.

[7] C. Liu, J. Shi, C. Gao and C. Niu, "Manganese oxide-based catalysts for lowtemperature selective catalytic reduction of NO x with NH 3: A review," Applied Catalysis A: General, vol. 522, pp. 64-69, 2016.

[8] C. E. P. Agency, "Heavy-Duty Technology and Fuels Assessment: Overview," Air resources board, 2015.

[9] P. Einewall, P. Tunestal and B. Johansson, "Lean Burn Natural Gas Operation vs.Stoichiometric Operation with EGR and a Three Way Catalyst," SAE technical paper, no. 2005-07-0250, 2005.

[10] S. Lee and R. Reitz, "Stoichiometric combustion in a HSDI diesel engine to allow use of a three-way exhaust catalyst," SAE Technical Paper, no. 2006-01-1148, 2006.

[11] S. Lee and R. Reitz, "Effects of engine operating parameters on near stoichiometric diesel combustion characteristics," SAE Technical Paper, no. 2007-01-0121, 2007.

[12] S. Chase, R. W. R. Nevin and K. Baumgard, "Stoichiometric compression ignition (SCI) Engine," SAE Technical Paper, no. 2007-01-4224, 2007. 
[13] C. Arcoumanis, C. Bae, R. Crookes and E. Kinoshita, "The potential of di-methyl ether (DME) as an alternative fuel for compression-ignition engines: A review," Fuel, vol. 87, pp. 1014-1030, 2008.

[14] J. Cha, S. Kwon and S. Park, "Engine performance and exhaust emissions in stoichiometric combustion engines fuelled with dimethyl ether," Proceedings of the Institution of Mechanical Engineers, Part D: Journal of Automobile Engineering, vol. 226, no. 5, pp. 674-683, 2012.

[15] S. Park and C. Lee, "Combustion performance and emission reduction characteristics of automotive DME engine system," Progress in Energy and Combustion Science, vol. 1, no. 39, pp. 147-168, 2013.

[16] I. Youn, S. Park, H. Roh and C. Lee, "Investigation on the fuel spray and emission reduction characteristics for dimethyl ether (DME) fueled multi-cylinder diesel engine with common-rail injection system," Fuel processing technology, vol. 7, no. 92, pp. 1280-1287, 2011.

[17] J. Hyung and H. Su, "Optimization study on exhaust emissions and fuel consumption in a dimethyl ther (DME) fueled diesel engine," Fuel, vol. 182, pp. 541-549, 2016.

[18] S. Park and S. Yoon, "Injection strategy for simultaneous reduction of NOx and soot emissions using two-stage injection in DME fueled engine," Applied energy, vol. 143, pp. 262-270, 2015.

[19] P. Sungwook, "Optimization of combustion chamber geometry and engine operating conditions for compression ignition engines fueled with dimethyl ether," Fuel, vol. 97, pp. 61-71, 2012.

[20] N. Allen, "High load Reactivity Controlled Compression Ignition (RCCI) Combustion in a Heavy Duty Engine," M.S. Thesis in Mechanical Engineering, University of Wisconsin - Madison, 2014.

[21] A. Amsden, "KIVA-3V, Release 2, Improvments to KIVA-3V. LA-UR-99-915," 1999.

[22] J. Beale and R. Reitz, "Modeling Spray Atomization with the KelvinHelmholtz/Rayleigh-Taylor Hybrid Model," Atomization and Sprays, vol. 9, pp. 623-650, 1999.

[23] Y. Ra and R. Reitz, "A reduced chemical kinetic model for IC engine combustion simulations with primary reference fuels.," Combustion and Flame, no. 155, pp. 713-738, 2008.

[24] N. Abani, A. Munnannur and R. Reitz, "Reduction of Numerical Parameter Dependencies in Diesel Spray Models," Journal of Engineering for Gas Turbines and Power, vol. 130, 2008.

[25] F. Perini, "Optimally reduced reaction mechanisms for Internal Combustion Engines running on biofuels," Ph.D. Thesis, University of Modena and Reggio Emilia, 2011.

[26] Z. Han and R. Reitz, "Turbulence Modeling of INternal Combustion Engines using RNG k-e Models," Combustion Science and Technology, vol. 106, pp. 267-295, 1995.

[27] S. Kokjohn and R. Reitz, "Investigation of the Roles of Flame Propagation, Rurbulent Mixing and Volumetric Heat Release in Conentional and Low 
Temperature Diesel Combustion," Journal of Engineering for Gas Turbines and Power, no. 133, 2011.

[28] L. Pan, S. Kokjohn and Z. Huang, "Development and validation of a reduced chemical kinetic model for dimethyl ether combustion," Fuel, vol. 160, pp. 165177, 2015.

[29] J. Abraham, "What Is Adequate Resolution in the Numerical Computation of Transient Jets," SAE International, no. 970051, 1997.

[30] N. Abani, S. L. Kokjohn, M. Park, S. W. Bergin, A. Munnannur, W. Ning, Y. Sun and R. D. Reitz, "An improved Sray MOdel for Reducing Numerical Parameters Dependencies in Diesel Engine CFD Simulations," SAE International, no. 200801-0970, 2008.

[31] A. Munnannur, "Droplet Collision Modeling In Multi-dimensional Engine Spray Computations," PHD Thesis in Mechanical Engineering, University of WisconsinMadison, 2007.

[32] P. O'Rourke and A. Amsden, "A Spray/Wall Interaction Submodel for the KIVA 3 Wall Film Model," SAE 2000-01-0271, 2000.

[33] L. Pan, S. Kokjohn and Z. Huang, "Development and validation of a reduced chemical kinetic model for dimethyl ether combustion," Fuel, vol. 160, pp. 165177, 2015.

[34] J. Benajes, R. Novella, J. Pastor, A. Hernández-López and S. Kokjohn, "Computational Optimization of the Combustion System of a Heavy Duty Direct Injection Diesel Engine Operating with Dimethyl-Ether," Fuel, 2017.

[35] D. Klos, "Investigations of Low Temperature Combustion Engine Desing and Combustion Stability," M.S. Thesis in Mechanical Engineering, University of Wisconsin - Madison, 2015.

[36] J. Benajes, R. Novell, D. De Lima, P. Tribotté, N. Quechon, P. Obernesser and V. Dugue, "Analysis of the combustion process, pollutant emissions and efficiency of an innovative 2-stroke HSDI engine designed for automotive applications," Applied Thermal Engineering, no. 58, pp. 181-193, 2013.

[37] California Environmental Protection Agency : Air Resources Board, 2017.

[38] Y. Lin and H. Zhang, "Component selection and smoothing in smoothing spline analysis of variance models," Annals of Statistics, vol. 5, no. 34, pp. 2272-2297, 2006.

[39] J. Arregle, J. López, J. Garcia and C. Fenollosa, "Development of a zerodimensional Diesel combustion model. Part 1: Analysis of the quasi-steady diffusion combustion phase," Applied Thermal Engineering, no. 23, p. 1301-1317, 2003.

[40] J. Arregle, J. López, J. Garcia and C. Fenollosa, "Development of a zerodimensional Diesel combustion model. Part 2: Analysis of the transient initial and final diffusion combustion phases," Applied Thermal Engineering, no. 23, p. 13191331, 2003. 